\title{
A depressão infantil e o pedagogo em cena
}

\author{
Childhood depression and the educator on stage \\ La depresión infantil y el educador en escena
}

Recebido: 11/12/2021 | Revisado: 16/12/2021 | Aceito: 18/12/2021 | Publicado: 20/12/2021

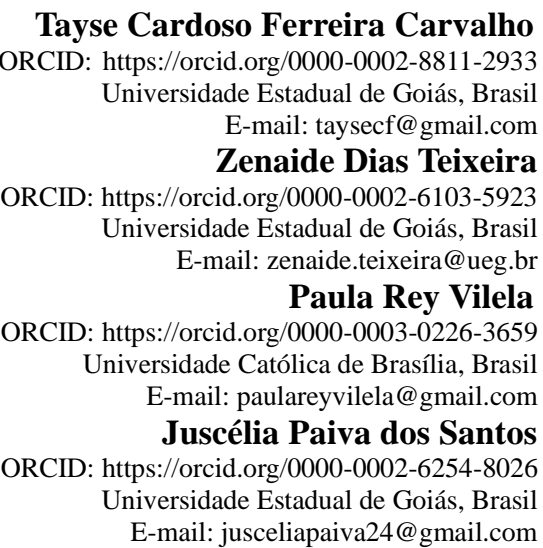

\begin{abstract}
Resumo
O presente trabalho tem como finalidade apresentar estudo de campo sobre a depressão infantil e o processo de ensino-aprendizagem, buscando, mais especificamente, discutir a importância do papel do professor. Diante de sua recente comprovação na infância, muitas vezes a depressão infantil passa despercebida. E por afetar muitos aspectos da vida da criança, inclusive o processo de ensino-aprendizagem, partimos do pressuposto de que o professor possa exercer um papel fundamental na identificação da criança acometida pela depressão, o que é um grande desafio. Para isso, realizamos uma pesquisa de campo, com aplicação de um questionário por meio do Google Forms para 29 estudantes do último semestre do curso de pedagogia de uma universidade pública no estado de Goiás, buscando perceber os conhecimentos dos futuros professores a respeito do tema. Os resultados da pesquisa demonstram que apesar de julgarem como importante que sua formação contemple conhecimentos básicos sobre a depressão infantil, a maioria dos estudantes, que estão no último semestre do curso de pedagogia e, portanto, em breve estarão em sala de aula, avaliam as orientações recebidas sobre o tema como insuficientes, portanto, não se sentem preparados para identificar ou lidar com crianças acometidas pela doença. Nesse sentido, chegamos à conclusão de que é necessário ampliar os conhecimentos sobre este transtorno, sobre seus sintomas e como ocorre na infância. Assim, o professor poderá auxiliar muitos de seus alunos a receberem um maior cuidado, alertar os responsáveis para que se possa procurar ajuda profissional adequada e a criança poderá receber tratamento o mais breve possível. Quanto antes ela for encaminhada para profissionais, mais resultados positivos são manifestados no tratamento e os danos à vida da criança, bem como ao processo de ensino-aprendizagem, podem ser significativamente minimizados.
\end{abstract}

Palavras-chave: Crianças; Depressão; Escolaridade; Professores.

\begin{abstract}
This paper aims to present a field study on childhood depression and the teaching-learning process, seeking, more specifically, to discuss the importance of the teacher's role. Given its recent evidence in childhood, childhood depression often goes unnoticed. And because it affects many aspects of the child's life, including the teachinglearning process, we assume that the teacher can play a fundamental role in identifying the child affected by depression. Therefore, this has been a challenge faced by several teachers involved in the teaching and learning process in general. For this, we carried out a field research, with the application of a questionnaire through Google Forms to 29 students in the last semester of the pedagogy course at a public university in the state of Goiás, seeking to understand the knowledge of future teachers on the subject. The research results show that although they believe it is important that their training includes basic knowledge about childhood depression, most students, who are in the last semester of the pedagogy course and, therefore, will soon be in the classroom, assess the guidance received on the subject as insufficient, therefore, they do not feel prepared to identify or deal with children affected by the disease. Therefore, it is necessary to have greater knowledge of the disorder, its symptoms and how it occurs in childhood. Thus, you will be able to help many of your students to receive greater care and alert those responsible so that they can seek adequate professional help and the child can receive treatment as soon as possible. The sooner it is referred
\end{abstract}


to professionals, the more positive results are manifested in the treatment and the damage to the child's life, as well as in the teaching-learning process, can be significantly minimized.

Keywords: Children; Depression; Schooling; Teachers.

\section{Resumen}

Este artículo tiene como objetivo presentar un estudio de campo sobre la depresión infantil y el proceso de enseñanzaaprendizaje, buscando, más específicamente, discutir la importancia del rol del docente. Dada su evidencia reciente en la infancia, la depresión infantil a menudo pasa desapercibida. Y debido a que afecta muchos aspectos de la vida del niño, incluido el proceso de enseñanza-aprendizaje, asumimos que el maestro puede jugar un papel fundamental en la identificación del niño afectado por la depresión. Por lo tanto, este ha sido un desafío al que se han enfrentado varios docentes involucrados en el proceso de enseñanza y aprendizaje en general. Para ello, realizamos una investigación de campo, con la aplicación de un cuestionario a través de Google Forms a 29 alumnos del último semestre del curso de pedagogía de una universidad pública del estado de Goiás, buscando comprender el conocimiento de los futuros docentes sobre la sujeto. Los resultados de la investigación muestran que si bien creen que es importante que su formación incluya conocimientos básicos sobre la depresión infantil, la mayoría de los estudiantes, que se encuentran en el último semestre del curso de pedagogía y, por lo tanto, pronto estarán en el aula, evalúan la orientación recibida en el tema como insuficiente, por lo tanto, no se sienten preparados para identificar o tratar a los niños afectados por la enfermedad. Por tanto, es necesario tener un mayor conocimiento del trastorno, sus síntomas y cómo se presenta en la infancia. Así, podrás ayudar a muchos de tus alumnos a recibir una mayor atención y alertar a los responsables para que puedan buscar la ayuda profesional adecuada y el niño pueda recibir tratamiento lo antes posible. Cuanto antes se remite a los profesionales, más resultados positivos se manifiestan en el tratamiento y el daño a la vida del niño, así como en el proceso de enseñanza-aprendizaje, se puede minimizar significativamente.

Palabras clave: Niños; Depresión; Enseñanza; Profesores.

\section{Introdução}

Os múltiplos impasses decorrentes da globalização e do avanço tecnológico afetam os diversos âmbitos da vida humana. Nota-se como reflexo deste contexto o surgimento de muitos transtornos psíquicos, como a depressão, que passou até a ser considerada como uma epidemia.

As novas formas de vida impostas ao homem moderno acentuam seu sentimento de desamparo e a existência de tantos doentes. Mas não podemos perder de vista a indústria farmacêutica. A psicofarmacologia que oferece recursos para a supressão dos sintomas da depressão, ao mesmo tempo reduz a pessoa à sua sintomatologia e em vez de considerar a sua subjetividade, o que favorece a continuidade da existência da depressão. Assim, o significante depressão abarca hoje todas as tonalidades de mal estar. Seja pela manutenção da doença e do fármaco, pela intolerância ao desamparo, pela forma agressiva de vida.

Outro grande empecilho aos nossos tempos que se junta à depressão é a pandemia COVID-19. Os casos de estresse e ansiedade certamente aumentaram durante a pandemia. Quem já tinha o diagnóstico também se encontra em uma situação delicada. Surge a perda de empregos e falência de empresas, as incertezas, o isolamento social, o medo de ser contagiado pela doença. Estes são fortes gatilhos que pioram o quadro emocional e psíquico.

Ademais, o uso desmedido das redes sociais no ambiente virtual pode repercutir em mal-estar e adoecimento nas pessoas. Neste contexto, são construídas representações de realidades ideais em contraposição a realidades singulares. Surgem comunidades mostrando-se com uma maior necessidade de transmitir a construção de uma imagem perfeita para ser estampada, tornando o processo de conhecimento acerca da depressão bastante complexo.

A moral imperativa na contemporaneidade é a da exaltação do eu e do exibicionismo. É a cultura do narcisismo com suas consequências. Birman (2005) nos ensina que na cultura da exaltação desmesurada do eu, não existe nenhum lugar para os deprimidos. Tais individualidades não conseguem realizar a tão esperada exaltação de si mesmo e se dedicar a figurinos maneiros para se mostrar com brilho na cena social. Maia (2002) também questiona o desmesurado culto ao narcisismo e ao mundo dos iguais, em que não há espaço para a diferença, para a alteridade. Sob este paradigma a civilização moderna tem sido construída. 
Soma-se a estas problematizações, a semiologia de um transtorno que apresenta sinais e sintomas silenciosos, podendo surgir dificuldades na sua identificação pelos pais, responsáveis e professores, sobretudo quando não se tem conhecimentos especializados.

Estas dificuldades tendem a acentuar-se na infância, que é uma fase totalmente diferente da fase adulta, em que a criança, sobretudo aquela que não adquiriu a fala, expressa-se numa comunicação que não é verbal. E mesmo quando o seu mundo já pode ser representado, simbolizado, ele nem sempre vem expresso na fala. Assim, a criança em estado depressivo pode não conseguir expressar oralmente seus sentimentos, mas poderá apresentar mudanças no modo de reagir ao mundo. Pode acontecer de a criança ter dificuldade para se entender e para se expressar, fazendo então, com que seu sofrimento psíquico se agrave com o passar do tempo.

$\mathrm{Na}$ falta de uma intervenção precoce e o devido encaminhamento a profissionais especializados no tratamento, podese chegar a um estado grave da depressão. Neste caso, a criança estará sujeita a intervenções mais invasivas. O uso de medicamentos por exemplo, pode deixar marcas psicológicas que serão carregadas durante toda vida. Com esse ponto de vista, recorre-se a proposta vigotskyana. Ela contribui com um embasamento que possibilita a reflexão acerca da importância do papel que o professor pode exercer na vida de uma criança que tem depressão:

Na concepção vygostkyana, o meio social em que a criança se encontra inserida constitui, de fato, uma zona de desenvolvimento, na medida em que as pessoas mais experientes colocam-se como uma forma de consciência indireta que ajuda a criança a discernir melhor sua experiência e, consequentemente, sair da indiferenciação inicial. (Vygotsky apud Palangana, 1995, p. 141).

Ao partir do pressuposto e da compreensão de que vivemos um dos séculos mais depressivos da história, faz-se necessário um estudo sobre a depressão em crianças. Este transtorno, dependendo do grau e modo em que se manifesta, pode afetar todos os âmbitos da vida da pessoa.

Nesta pesquisa, optou-se por aprofundar a reflexão sobre a importância da formação do professor para a identificação da criança acometida pela depressão, tendo em vista que a doença pode afetar o processo de ensino-aprendizagem. Desse modo, ressalta-se seu papel como um importante agente da rede social da criança a perceber seus sintomas. Ao ter maior compreensão deste sofrimento, poderá encaminhar a criança para atendimento especializado o mais breve possível, minimizando as consequências da depressão em sua vida e, particularmente, no processo de ensino-aprendizagem.

\section{Metodologia}

A metodologia utilizada para desenvolver este trabalho é de natureza aplicada, de abordagem qualitativa, na modalidade de estudo de campo em uma universidade pública no estado de Goiás, com 29 estudantes do último semestre do curso de pedagogia por meio da técnica de coleta de dados questionário fechado, realizado no Google Forms. Buscando perceber os conhecimentos dos futuros professores a respeito do tema.

A investigação qualitativa é a que mais se adequa a este estudo. Pois segundo Bogdan e Biklen (1994) investigação qualitativa pois permite um contato direto do pesquisador com a fonte direta dos dados no ambiente que está sendo elucidada a questão investigativa. Para os autores:

"Ainda que os indivíduos que fazem investigação qualitativa possam vir a seleccionar (sic) questões específicas à medida que recolhem os dados, a abordagem à investigação não é feita com o objectivo (sic) de responder a questões prévias ou de testar hipóteses. Privilegiam, essencialmente, a compreensão dos comportamentos a partir da perspectiva dos sujeitos da investigação. As causas exteriores são consideradas de importância secundária". (Bogdan \& Biklen, 1994, p. 17). 
A pesquisa qualitativa permite levar em consideração a relação ativa entre o ambiente e o indivíduo, gerando um certo vinculo entre o objeto de estudo e a subjetividade. Assim, a partir dos dados levantados por meio da revisão bibliográfica e da técnica de questionário fechado foi feita análise dos dados sendo representados por meio de gráfico. Sendo realizado um minucioso planejamento de cada etapa, tanto da coleta dos dados quanto da tabulação e análise. Tendo em vista que a "abordagem da investigação qualitativa exige que o mundo seja examinado com a ideia de que nada é trivial, que tudo tem potencial para construir uma pista que nos permita estabelecer uma compreensão mais esclarecedora do nosso objeto de estudo". (Bogdan \& Biklen, 1994).

Segundo Gil (1999), a utilização dessa abordagem permite o aprofundamento das questões relacionadas ao fenômeno estudado e as suas relações, sendo permitida pela valorização de um maior contato direto com a situação em estudo, buscandose o que era comum, mas permanecendo, entretanto, aberta para perceber a individualidade e os significados múltiplos.

\section{Resultados e Discussão}

\subsection{A semiologia da depressão na modernidade: contribuições da psicopatologia e psicanálise}

A depressão é um transtorno do humor que abrange um conjunto de sintomas (Miller, 2003). Tem como características: melancolia, tristeza, baixa autoestima, sentimento de culpa, falta de ânimo e vontade de isolamento, podendo, em casos extremos, chegar ao desejo de tirar a própria vida. Segundo o DSM-V (2014), as consequências funcionais da depressão podem chegar à incapacidade total, como não conseguir mais cuidar de sua própria higiene, falar, ter o funcionamento físico reduzido e, consequentemente, aumentar o risco de doenças físicas.

É importante assinalar que dentro da depressão, a tristeza é um sintoma. Mas fora da doença, ela é presente em todo e qualquer ser humano como sentimento, sendo até mesmo necessária para o desenvolvimento. Já a melancolia, por vezes, é até confundida com a doença.

Nota-se que a melancolia apresentada por Freud em seu texto "Luto e Melancolia" de 1917, tem facilmente se igualado a sentimentos que dizem respeito ao desamparo inerente, vivenciado durante toda a vida de um indivíduo.

Importante considerar que em Freud (1917), a melancolia é um luto permanente por algo em que não se sabe descrever, que não se trata do consciente, ou seja, se refere a um luto por idealização. Há uma impossibilidade permanente de o sujeito fazer o luto pelo objeto perdido. Sem saber do que se trata, o que foi perdido, a pessoa não consegue ir se desprendendo aos poucos, como no luto comum. Assim o sujeito identifica-se com tal objeto em uma base que Freud denominou de narcísica. Em sua frase modelo Freud afirma que a sombra do objeto recai sobre o eu. $\mathrm{O}$ discurso que o melancólico produz é feito de autocríticas. Assim como no luto, há uma perda do amor próprio, do interesse pelo mundo externo, da capacidade de amar, além de um desânimo e uma inibição por qualquer atividade. Mas na melancolia há uma acentuada diminuição dos sentimentos de autoestima. O melancólico se auto recrimina e, como consequência, se pune por isso. Freud (1914) denominou neuroses narcísicas como afecções do tipo da melancolia.

Já o luto fora da melancolia, é passageiro, pois trata-se de um período seguinte a perda de algo ou alguém, por exemplo. Freud (1917) esclarece que o trabalho que o luto realiza é aquele que diz que o objeto amado não existe mais e que a libido, antes investida nesse objeto precisa ser retirada deste e seguir outros caminhos. O luto obriga o eu a desistir do objeto, declarando-o morto e oferecendo ao eu o incentivo de continuar a viver. Este processo torna-se possível, pois, o que ocorre é a reação a uma perda consciente de um objeto amado, há uma perda real, o sujeito sabe o que perdeu. Não há nada de inconsciente a respeito da perda, ou seja, não há nada desconhecido, ou numa outra cena como diz Freud ao referir-se ao inconsciente. Mas isso não quer dizer que seu processo não seja doloroso. 
Para sair da dor, porém, o luto enquanto reação à perda de um objeto amado torna-se necessário, e neste sentido, não pode ser considerado como sendo uma condição patológica que necessite de um tratamento médico. Ainda assim, Freud evidencia neste processo graves afastamentos daquilo que constitui a atitude normal para com a vida.

O que se apresenta no luto é um desânimo profundamente penoso, a cessação de interesse pelo mundo externo, a perda da capacidade de amar e a inibição de toda e qualquer atividade. A inibição e a perda de interesse são plenamente explicadas pelo trabalho do luto no qual o eu é absorvido.

Este trabalho do luto tem sido uma constante no homem da modernidade. Isso porque de certa forma, a civilização atua em seu favor. As grandes e aceleradas mudanças decorrentes do século das luzes transmitem insegurança e acentuam o sentimento de desamparo no sujeito.

O que parece estar em questão é que o moderno tem como premissa a ordem. Assim diz Maia (2002):

O moderno toma a ordem como tarefa: é preciso ordenar, classificar e purificar, tornar legível e sem ambiguidades qualquer objeto que se candidate aos métodos de investigação. O moderno tem horror à incerteza, à ambivalência. Como a ordem, no entanto só se positiva sobre a negatividade do caos, a modernidade se constrói nessa polaridade. Tudo que resiste à clareza da ordem se torna caótico e precisa ser excluído em prol do progresso, outra palavra soberana neste período (Maia, 2002, p.86).

Com isso, são as neurociências, o cognitivismo e a psicofarmacologia que prometem acabar com este desamparo. A indústria farmacêutica, que se ampliou no século XX quando introduziu os antidepressivos, é neste sentido, grande colaboradora pela existência de diagnósticos que transformam o luto ou uma simples tristeza em doença. Mas o que tem se tornado comum no campo psiquiátrico é a indistinção daquilo que caracteriza a melancolia e a depressão e o uso indiscriminado de medicamentos antidepressivos para qualquer forma de tristeza.

Atualmente, os critérios para diagnosticar transtornos psiquiátricos baseiam-se excessivamente nos sinais e sintomas aparentes. Neste sentido, a divisão clássica endógena, exógena e psicogênica que repousa em um diagnóstico etiológico, vai gradativamente perdendo o terreno, cedendo lugar para uma visão eminentemente sintomática.

No DSM IV (1994), a melancolia é incluída como uma característica do transtorno depressivo maior e na CID 10 a palavra melancolia não aparece, mas se "dissolve" nas categorias dos transtornos do humor. Pela CID 10 (1993), os transtornos do humor são apresentados como mania, psicose maníaco depressiva e depressão. Estes agrupamentos contêm as seguintes categorias de três caracteres. A seguir, apresentamos o Quadro 1:

Quadro 1. A Classificação Internacional das Doenças, da Organização Mundial da Saúde, em sua décima revisão.

\begin{tabular}{|l|l|}
\hline F30 & Episódio maníaco (usado para episódio único de mania). \\
\hline F31 & Transtorno afetivo bipolar. \\
\hline F32 & Episódio depressivo (usado para episódio depressivo único). \\
\hline F33 & $\begin{array}{l}\text { Transtorno depressivo recorrente (tem as mesmas subdivisões descritas para o episódio } \\
\text { depressivo). }\end{array}$ \\
\hline F34 & Transtornos persistentes do humor. \\
\hline F38 & Outros transtornos do humor. \\
\hline F39 & Transtorno do humor não especificado. \\
\hline
\end{tabular}

Fonte: CID10 (1993).

A depressão conforme Andriola e Cavalcante (1999) pode estar ligada a três fatores: o aspecto biológico, o aspecto de personalidade e também o aspecto social. Do ponto de vista biológico, a depressão é vista como uma possível disfunção dos neurotransmissores devido à herança genética. No ponto de vista psicológico, a depressão pode estar associada aos aspectos relacionados a personalidade, baixa auto estima e autoconfiança. Já na perspectiva social pode estar associada a inadaptação ou 
pedido de socorro em consequência de violentação de mecanismos culturais, familiares, escolares, etc. (Barreto, 1993 apud Andriola \& Cavalcante, 1999).

Existem tipos diferentes de depressão, vejamos alguns dos mais conhecidos. O transtorno depressivo maior, também chamado de depressão unipolar, se trata do mais frequente e também mais conhecido. Além da perda de prazer e interesse, é marcado pelo sofrimento e melancolia. A depressão bipolar não é sinônimo do transtorno bipolar, mas possui alternância entre grande euforia e momentos em que satisfaz os critérios de depressão maior, além de ter mania ou hipomania.

$\mathrm{Na}$ distimia, que é o transtorno depressivo persistente, o acometido tem tristeza, desânimo, pessimismo e se trata de uma depressão crônica, havendo um consenso de uma duração mínima de 2 anos. Na depressão pós-parto os sintomas podem ser observados desde a gestação até semanas após o nascimento. É marcada por uma ansiedade não sadia, diferente daquela que as mães não depressivas experimentam. Pode ainda haver um sentimento de exaustão prejudicial à mãe e ao bebê, uma vez que não há energia para os cuidados com a criança.

A depressão reativa é causada por um evento específico, um trauma, a morte de um ente querido, um acontecimento como a perda de um emprego ou de bens materiais. Mesmo sendo normais a tristeza por esses fatos, há quem não consiga superá-los, tendo comportamentos como o isolamento e insegurança, fazendo com que a doença seja desencadeada ou para quem já tem pré-disposição, funcionando como um gatilho.

Quem sofre de depressão atípica tem variações de humor temporários, reagindo muito bem a uma ótima notícia recebida, por exemplo, mas em seguida tudo volta a ser como era antes. Os sintomas são sono exagerado, ganho de peso, apatia, sentimento de rejeição. Por conta do pico de bom humor, que mascara o quadro do depressivo, por vezes é difícil identificar a doença.

A depressão sazonal não é comum em nosso país, sendo mais presente em lugares com invernos rigorosos e com pouca luz, como na Europa. A doença é marcada por ingestão compulsiva de doces, sonolência e cansaço extremos, alto nível de estresse e falta de ânimo. Já a depressão psicótica, ocorre quando o paciente tem um quadro depressivo extremamente severo e/ou tendência a alguma forma de psicose, com alucinações, sentidos de vozes ou imagens pertubadoras, delírios e ilusões.

Belk e Alford (2011) falam sobre os paradoxos da depressão, pois a imagem que a pessoa com o transtorno depressivo tem de si mesma, não confere com a realidade. Ou seja, mesmo que uma pessoa tenha muitos bens materiais, emprego estável, e o espectador não compreenda o por que o depressivo não se sinta realizado, quem tem a doença sente-se vazio, inútil, desprezível, pois o transtorno o faz sentir assim. Belk e Alford (2011) mostram que não há uma explicação suficiente para esses paradoxos, nem características de pessoas com depressão. Uma pessoa que tem transtorno ou episódio depressivo olha o seu cotidiano com a ótica da doença, e não como realmente é.

Lafer et al (2000) afirmam que o público mais atingido pela depressão são jovens e idosos, mas que não deixa de acontecer em crianças. Para eles, a depressão é um estorvo do humor austero e contínuo e não há faixa etária imune ao transtorno. Os autores mostram ainda que a depressão vem ganhando força neste século, o que ainda é um fator sem explicação.

Embora a característica mais típica dos estados depressivos seja a proeminência dos sentimentos de tristeza ou vazio, nem todos os pacientes relatam a sensação subjetiva de tristeza. Muitos referem, sobretudo, à perda da capacidade de experimentar prazer nas atividades em geral e à redução do interesse pelo ambiente” (Del Porto, 1999, p.7).

Uma das principais dificuldades para o diagnóstico precoce da depressão é o fato de que tais sintomas são comumente confundidos com mera preguiça ou desinteresse do sujeito, o que dificulta a percepção da patologia pelos adultos que convivem com a criança acometida pela doença. 


\subsection{A depressão em crianças}

Conforme Jean-Jaques Hemery (2008), a família constitui o primeiro meio que a criança tem para socialização com o mundo e constituição de sua personalidade, somente mais tarde ela passa a se relacionar com os demais ambientes, entre eles a escola, que é um local privilegiado para a participação direta na vida das crianças. Segundo Vygostky (1988), o desenvolvimento se dá a partir da interação, e na escola as crianças interagem com várias pessoas diferentes, e "juntamente com a linguagem são internalizados valores, significados, regras de conduta, enfim, formas culturais de comportamento" (Vygotsky apud Palangana1995, p. 141).

Até 1960 acreditava-se que a depressão não atingia as crianças, o que foi refutado por Baptista e Golfeto (2000), Andriola e Cavalcante (1999) e Soares (2003). A depressão se manifesta de forma evidente em crianças ainda na fase préescolar, por meio de irritabilidades, desregulamento de sono e apetite, hiperatividade, dores, fobias, ansiedade, ausência ou falta de prazer em atividades de antes (Bahls, 2004).

Ao longo dos últimos anos pode-se observar uma elevação gradativa do número de pessoas com depressão, incluindo o período da infância e da adolescência, conforme observa Nakamura e Santos $(2007$, p. 2) "tem se mostrado mais evidente desde a década de 1970, quando aumentou o interesse no campo da investigação e no meio acadêmico e reconheceu-se a presença significativa desse distúrbio entre crianças e adolescentes", a partir desse momento surge a necessidade de elevação de pesquisas acerca da temática, objetivando torná-la mais conhecida entre toda a população.

Vários fatores são levados em consideração para a manifestação de depressão em crianças, como traumas e/ou uso de químicas durante a gestação, complicações no parto, históricos de distúrbios e transtornos na família, excesso de atividades extracurriculares, a superproteção de pais, excesso de cobranças, ou mesmo negligência em relação aos cuidados afetivos, a falta de resposta e reciprocidade por parte das pessoas que são responsáveis pelo zelo das crianças quanto às suas emoções e sentimentos, entre outros.

A depressão infantil pode ser subdividida de forma resumida em duas classes: a unipolar e a bipolar, e diferenciar uma da outra pode não ser simples, mas é muito importante. Para a depressão bipolar, o uso de estabilizadores de humor é de suma importância no tratamento para que não haja piora do quadro da criança. Acontecem casos em que a criança possui um quadro unipolar e converte para um quadro bipolar, tornando o quadro mais difícil de ser tratado e podendo ser sinal de que não houve tratamento inicial ou este não foi eficaz. O DSM-V traz uma importante informação sobre crianças que possuem descontroles de comportamento, irritabilidade e de humor, típicas da bipolaridade: essas crianças, ao entrarem na adolescência, têm enorme possibilidade de tornarem-se depressivas.

A classe unipolar é marcada pelos sintomas presentes na depressão maior e na distimia: sentimento de inutilidade, desejo de morte, melancolia, sono excessivo ou ausência de sono, falta de ânimo. Já a classe bipolar está presente na depressão que possui grande variação, gerando a euforia, em que se ri e conversa muito, se tem elevada autoestima, podendo esse período durar algumas horas, alguns dias, dependendo do quadro e da causa.

Muitas vezes a depressão infantil é ignorada porque as pessoas não conhecem o nível de sua gravidade. Também por não estarem cientes de que crianças podem ser acometidas pela depressão. Segundo Marcelli (1998), nenhum dos sinais devem ser observados separadamente, sendo necessária a avaliação do conjunto, do período em que se está vivendo e da durabilidade das crises. Andriola e Cavalcante (1999) mostram que cerca de cinco por cento de crianças e adolescentes, contabilizando a população geral, têm um grau de depressão. A falta de informação por parte dos pais e da comunidade escolar também influência no agravamento da doença:

A falta de informações de pais e professores sobre a depressão infantil pode contribuir para aumentar as dificuldades dos alunos e causar inúmeras sequelas emocionais no futuro. É evidente que família e educadores não estão 
preparados para fazer um diagnóstico na criança. Cabe ressaltar que nem é esse o papel dos mesmos. No entanto, um olhar mais atento a essas crianças permite que sejam reconhecidas mais cedo e encaminhadas para um diagnóstico mais cuidadoso associado à intervenção necessária (Cruvinel, 2003, p. 29).

Infelizmente, grande parte da população que sofre com o transtorno não é interpretada da forma correta e acaba não recebendo o tratamento que deveria. Durante a infância, quando a criança demonstra certos comportamentos, os pais e pessoas que convivem tendem a achar que é apenas vontade de chamar atenção e acabam repreendendo a criança. Esta atitude pode ser o ápice para tornar a depressão ainda mais severa. Os sintomas comumente observados entre as crianças com depressão são:

As condutas de oposição, a hostilidade, a instabilidade de humor, as crises de raiva são comuns e muitas vezes são as manifestações centrais do quadro clínico. Esses afetos negativos podem ser desencadeados por motivos fúteis. A lentificação tanto psíquica quanto motora está presente, mas nem sempre é muito evidente. A ação e a expressão estão alteradas, inibidas, e suas repercussões são notadas na indiferença, no desinteresse tanto por atividades habituais de rotina, como atividades escolares e brincadeiras. A criança geralmente se isola e evita o contato. A comunicação verbal e/ou não-verbal fica comprometida e as respostas podem ser lentificadas e breves. A mímica é pobre e pouco expressiva. Muitas vezes o que se vê é uma perda do entusiasmo e as atividades ficam sendo feitas mecanicamente, apenas por obrigação. $O$ rendimento escolar também diminui, tanto pelo desinteresse quanto pela falta de concentração e por dificuldades de raciocínio. Quanto às queixas físicas, a alimentação e o sono podem estar alterados. As crianças tendem a expressar a sensação de mal-estar através de queixas somáticas. Os casos mais graves podem cursar com sintomas delirantes e alucinatórios (Curatolo \& Brasil, 2005, p. 171- 172).

Os sintomas da depressão podem se apresentar de formas variadas, crianças e adolescentes depressivos podem apresentar tristeza, desmotivação, irritabilidade, negativismo, sentimentos de inutilidade, comportamentos agressivos, prédisposição para brigas, alterações de sono, mudanças no rendimento escolar, queixas somáticas e mudanças de apetite.(Baptista et al 2018). Os sintomas da depressão em crianças e adolescentes podem ser similares aos de adultos, porém pode apresentar repercussões ainda mais negativas. Ademais, a depressão apresentada ainda na infância ou adolescência pode afetar algumas funções do desenvolvimento tanto cognitivas quanto afetivas e pscicosociais que incapacitam o funcionamento do indivíduo (American Psyquiatric Association, APA, 2014 apud Baptista 2018).

As crianças quando estão depressivas apresentam sintomas que afetam tanto o cognitivo quanto o emocional. Piaget, em seu livro Seis estudos de psicologia (1967), mostra que para o desenvolvimento integral da criança é necessário que o afetivo e o intelecto sejam sempre trabalhados juntos. Para ele, a emoção e o cognitivo são inseparáveis. Sendo assim, nota-se que uma criança com depressão está passível a um bloqueio no seu desenvolvimento.

Infelizmente, a criança não possui a mesma facilidade que um adulto para entender o que se passa com ela. E como o autoconhecimento é uma tarefa árdua e difícil até para os mais velhos, acaba por pensar que está passando por algo comum, que as outras pessoas também se sentem assim. Quando os responsáveis ou professores não notam os sintomas e o depressivo não é diagnosticado corretamente e nem recebe o tratamento adequado, pode haver piora no quadro e desenvolver vários outros distúrbios. Darwich e Tourinho (2005) revelam a depressão como:

o sentimento de uma fadiga absoluta, o esgotamento total de suas forças. A impressão é acompanhada, na grande maioria das vezes, da certeza de que esse estado será duradouro. O pânico surge e dissemina esse medo de quase tudo. É um sentimento da morte estando vivo, uma fraqueza do ser, um desencanto absoluto. E o deprimido sente que a vida não tem sentido (Darwich \& Tourinho, 2005 p.11).

Ainda existe muito antagonismo em relação ao diagnóstico da depressão na infância, e pouca literatura sobre a questão. Segundo o Manual Diagnóstico e Estatístico de Transtornos Mentais - DSM IV (1994), desde que se leve em 
consideração fatores como idade e fase de desenvolvimento, não há mudança quanto à depressão em um adulto. Rehm e Sharp (1999) refutam, afirmando que a doença não se manifesta como na fase adulta e não deve ser diagnosticada de forma semelhante.

Quanto mais cedo é realizado o diagnóstico e iniciado o tratamento adequado, maior é a probabilidade de recuperação total da criança. O tratamento implica desde terapias semanais, quinzenais ou mensais, mudanças do cotidiano, até o acompanhamento psiquiátrico, com o uso de medicamentos. Esta é a última instância em decorrência da saúde da criança e para que não corra o risco de desenvolver vício ou até mesmo síndrome da descontinuação de antidepressivos. Um tratamento adequado possibilita que a criança possa retomar seus estudos com o máximo de aproveitamento e sem grandes prejuízos para o seu cognitivo. Ressalta-se que "as áreas cognitivas que mais são afetadas são a atenção e concentração" (Lemos \& Marback, 2016, p.378), que são essenciais para a aprendizagem da criança.

Uma criança com sintomas depressivos pode vir a apresentar sérios problemas de comportamento nas relações sociais e familiares, bem como no desenvolvimento cognitivo, escolar e emocional. Baptista (1999, p.42) afirma que "apesar das controvérsias e dificuldades no diagnóstico, é sabido que na depressão, tanto na criança como no adulto, ocorre alterações no funcionamento do indivíduo, como forma de pensar e agir".

A incidência de problemas emocionais, especificamente da depressão, é percebida com mais frequência em idade escolar, uma vez que a depressão infantil pode causar dificuldades de comportamento e aprendizagem. Segundo Fonseca (1998, p.164), "os problemas psicológicos infantis não devem ser considerados como fenômeno transitório e sem gravidade".

É valido ressaltar a importância do diagnóstico para a família, uma vez que os sintomas da depressão podem trazer mudanças comportamentais, variando desde extrema irritabilidade à obediência excessiva, podendo ainda causar instabilidade em relação a esses comportamentos. (Barbosa \& Lucena, 1995).

Outro fator que pode ser relevante apontado por Milavic (1985), são crianças que possuem pais depressivos serem propensas a desenvolver a depressão, pois além da provável imitação dos comportamentos depressivos dos pais (gerando assim, a depressão denominada exógena), há também a possibilidade da herança genética (que caracteriza a depressão endógena.

Com a pandemia Covid-19, a nossa hipótese é de que a depressão infantil pode ocorrer com mais frequência, mas ser percebida mais tardiamente pois, devido ao isolamento social, as crianças não puderam mais ir às escolas, tendo aulas de forma remota, e assim, ficando afastadas de seus colegas e professores. É fato que muitos pais passaram a ficar mais tempo em casa com o advento do home office, mas isso não significa mais tempo com os filhos, já que os pais que trabalham remotamente dedicam a maior parte de seu tempo diário ao trabalho.

Não foi raro ver noticiários sobre o grande aumento nos índices de depressão neste tempo de isolamento social: a grande quebra de rotina, o medo da morte, a angústia em não poder conviver com as pessoas queridas, a incerteza de quando (e se) a vida voltará ao normal, são fatores que influenciam muito o bem-estar psíquico e emocional do ser humano.

\section{A Depressão Infantil e o Papel do Professor}

A depressão em crianças não é algo que deva ser tratado como um problema da família ou do indivíduo. A escola tem a importante função de identificar possíveis sintomas, comunicar os pais e ajudar no encaminhamento para profissionais qualificados para avaliar e, se preciso, tratar a criança. Nessa perspectiva, é relevante que os docentes tenham conhecimentos básicos sobre a doença e seus sintomas. Assim podem auxiliar na identificação de possível acometimento da criança pela doença. A escola também é importante porque, às vezes, as doenças não são manifestadas antes dela. Conforme Miller (2003 p. 8) "vários distúrbios emocionais e comportamentais em crianças não são percebidos até que elas comecem a educação formal. [...] crianças com depressão costumam ser calmas e obedientes, e não causam confusões". 
O principal ecossistema da criança além de sua família é a escola. O início da escolarização é uma mudança significativa em sua vida. Toda a rotina é quebrada, o convívio com muitas pessoas ao mesmo tempo é inserido, a submissão a novas autoridades, a necessidade do compartilhamento de materiais são algumas destas mudanças. Todo esse novo contexto causa sentimentos que, em princípio, parecem confusos, mas são necessários e fazem parte do desenvolvimento. Quando adequadamente trabalhados tanto pela escola quanto pela família, são rapidamente superados. Mas, a escola também pode ser a desencadeadora da depressão. A perda do interesse da criança pela escola pode ser sinal de que ela não esteja se relacionando bem com colegas ou professores, que teve algum evento traumático, que esteja sofrendo bullying ou algum outro evento específico.

Outro fator que pode tornar a escola desencadeadora da depressão é a competitividade escolar. Esta situação provoca os alunos a terem as melhores notas (que, diga-se de passagem, não necessariamente significa aprendizagem), promovendo uma concorrência sem sentido. Essa concorrência pode causar um sentimento de incapacidade na criança, o que pode ser um gatilho depressivo, levando a criança a abrir mão de tentar, mesmo tendo potencial para isso.

A depressão, por mais que tenha como característica mais evidente a transição de humores, não influencia somente o afetivo, mas outras diversas áreas como a cognitiva e fisiológica. Os sintomas, quando não avaliados em seu contexto, acabam fazendo com que a criança tenha comportamentos piores, consciente ou inconscientemente, na busca por se expressar. Segundo Miller (2003 p.9), "normalmente, elas só recebem tratamento quando agem de maneira drástica ao faltar às aulas com frequência, irritar-se, frustrar-se nas aulas ou tentar o suicídio".

É importante ressaltar que a depressão não tem vínculo algum com déficit de capacidade, não torna a criança menos inteligente, a dificuldade no aprendizado pode ocorrer por consequência da falta de interesse, do sentimento de ser inútil e sem valor, além dos demais sintomas. Conforme (Vygotsky et al., 1988 apud Lima \& 2006, p. 186), "o aprendizado é um aspecto necessário e universal para o desenvolvimento das funções psicológicas culturalmente organizadas e particularmente humanas". Porém, os autores concordam que há condições que podem atrapalhar no processo de aprendizagem, e uma dessas condições pode ser a depressão infantil.

A infância é uma fase de diversas mudanças, variações afetivas, descobertas, adaptações e também o período em que as características da personalidade de cada um começam a tornar-se evidente. Observar o que é da personalidade da criança, distinguir seus comportamentos e conhecer os sintomas da depressão, pode livrar uma pessoa de ser mais uma entre os casos graves de depressão. Pode, ainda, melhorar ou até mesmo salvar uma vida, já que segundo Marcelli (1998), existe nas crianças depressivas o sentimento de que a vida não vale a pena.

O professor com conhecimentos básicos sobre a depressão infantil e um olhar atento para o comportamento e desenvolvimento de seus estudantes, pode ser um agente chave na identificação de um possível contexto de depressão e no encaminhamento da criança para tratamento. Por outro lado, a falta de conhecimento e sensibilidade para esta doença, pode levar o professor a considerar o aluno como apenas problemático, o que pode tardar muito a chegada da criança a especialistas para tratamento adequado.

Geralmente, são os professores que percebem os sintomas do transtorno de humor, antes dos pais da criança, pois os pedagogos possuem conhecimento mais aprofundado sobre o desenvolvimento infantil, além de dedicar uma atenção mais específica para a criança. Assim, corroborando com Bahls (2004), comumente os docentes são os primeiros a perceberem quando uma criança está com depressão, pois este quadro compromete o rendimento escolar desse aluno. Por mais que não seja obrigação do professor, seu papel é fundamental:

Embora o diagnóstico de depressão infantil não seja nem deva ser papel dos educadores, a escola e o professor desempenham uma função extremamente relevante no reconhecimento dos sintomas de depressão, uma vez que a 
presença da depressão de fato interfere no rendimento do aluno e também tende a influir no emprego de estratégias de aprendizagem. É possível que a queda no rendimento escolar possa ser utilizada como um sinal para os pais e professores de que algo não vai bem com aquela criança e esta pode estar vivenciando sintomas depressivos (Cruvinel \& Boruchovitch, 2003, p. 376).

A criança que demonstra dificuldade de socialização, humor variado, sintomas do transtorno depressivo acaba ficando cada vez mais isolada. Nesse contexto é primordial que haja mediação para que essa criança consiga fazer parte do grupo na escola:

o aprendizado desperta vários processos internos de desenvolvimento, que são capazes de operar somente quando a criança interage com as pessoas de seu ambiente e quando em cooperações com seus companheiros. Uma vez internalizados, esses processos tornam-se parte das aquisições do desenvolvimento independente da criança (Vygotsky, 2007, p. 103).

A depressão pode interferir no processo de aprendizagem das crianças, uma vez que crianças afetadas por essa patologia apresentam baixa auto estima e não conseguem acreditar em sua capacidade, levando a um baixo rendimento escolar. Sendo que, quanto mais sintomas depressivos, menor será o uso de estratégias de aprendizagem por parte da criança. (Rodrigues et al., 2016 apud Bordignon et al., 2019).

Quando uma criança tiver o diagnóstico de depressão, outra grande missão do professor é saber como lidar com ela. Não existe até o momento políticas públicas para o cuidado ou regulamentações com instruções de como o professor deve agir. Assim, torna-se fundamental conhecer a doença, e principalmente conhecer o aluno, para ser um incentivador, influenciar de forma positiva a afetividade, compreender suas limitações e respeitar o ritmo de aprendizagem do aluno. Esta postura é fundamental, já que uma cobrança demasiada poderá piorar os sintomas e agravar o diagnóstico. Conforme Miller (2003), quando a equipe escolar é preparada, tem capacidade de fornecer apoio que pode ajudar até mesmo na reversão do quadro.

Uma criança com depressão que não recebe tratamento e cuidados, na medida em que a doença se agrava, pode isolarse, tornar-se um aluno conturbado, ter ações exacerbadas e até mesmo cometer suicídio. Bauer (2007) retrata a importância de a escola ter ciência sobre esse transtorno de humor:

Desde que o transtorno depressivo em crianças e adolescentes na idade escolar envolva sintomatologia que interfira nas habilidades de aprendizagem, a educação deve ser instruída quanto às intervenções pedagógicas a partir dos conceitos de saúde e patologia física e mental, oportunizando práticas educacionais como atividades de promoção de saúde. É importante que as escolas reconheçam que a depressão pode se tornar um problema grave, vindo a gerar alterações no funcionamento social e acadêmico de seus alunos (Bauer, 2007, p. 21).

Com isso, evidencia-se que todo o corpo escolar deve estar atento ao comportamento dos educandos. os professores têm papel fundamental nesse processo, pois convivem boa parte do tempo com seus alunos e podem, juntamente dos pais, auxiliar na identificação dos problemas comportamentais das crianças. o docente também tem o papel de observar o desenvolvimento da criança em sala de aula e, com preparo e um olhar crítico, consegue perceber as dificuldades que uma criança possa estar enfrentando. mais do que o diagnóstico, é de suma importância que a criança depressiva tenha acompanhamento, pois conforme Lafer et al. (2000) há chances de reincidência futuras.

\section{A Preparação do Pedagogo para Lidar com a Depressão Infantil em Sala de Aula}

Conforme vimos discutindo, o professor - por seus conhecimentos sobre o desenvolvimento infantil, por conviver bastante tempo com seus estudantes e por dar a eles uma atenção especial - pode ser um agente fundamental na identificação 
de um possível contexto de depressão infantil. Mas será que sua formação lhe subsidia o suficiente para tal? Para analisar essa problemática, realizamos uma pesquisa de campo, com aplicação de um questionário por meio do Google Forms para 29 estudantes do último semestre do curso de pedagogia de uma universidade pública no estado de Goiás, buscando perceber os conhecimentos dos futuros professores a respeito do tema.

Nossa primeira pergunta buscou verificar se os futuros professores têm conhecimento sobre a possibilidade de a criança ser acometida pela depressão: "Você acha possível que as crianças possam desenvolver depressão?" 72,4\% dos sujeitos de pesquisas responderam que sim, portanto, podemos observar que a maioria tem essa consciência da possibilidade de desenvolvimento da depressão infantil. Os dados estão apresentados na Figura 1:

Figura 1. Possibilidade de as crianças desenvolverem depressão.

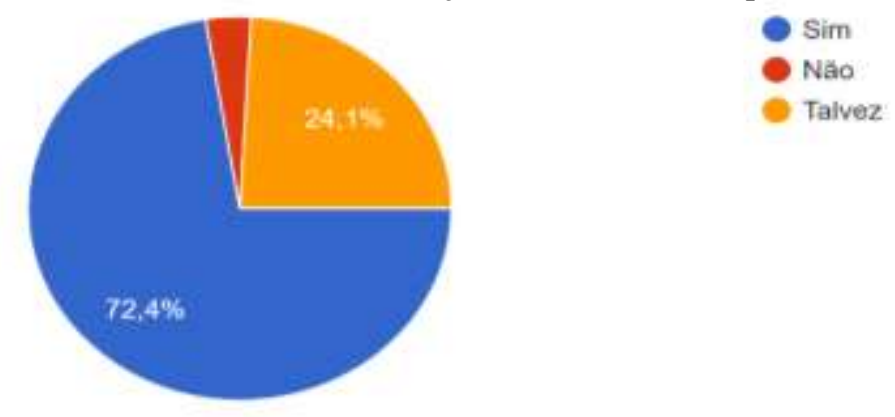

Fonte: Autores (2021).

Em seguida, buscamos verificar se a formação inicial do pedagogo prepara esse profissional para lidar com casos de depressão infantil em sala de aula: "Você se sente preparado para lidar com uma criança depressiva em sala de aula?” Podemos verificar que $93,1 \%$ dos estudantes, que em poucos meses estarão no mercado de trabalho, não se sentem preparados para lidar com uma situação de criança acometida pela depressão. Os dados estão apresentados na Figura 2:

Figura 2. Professor se sente preparado para lidar com criança depressiva.

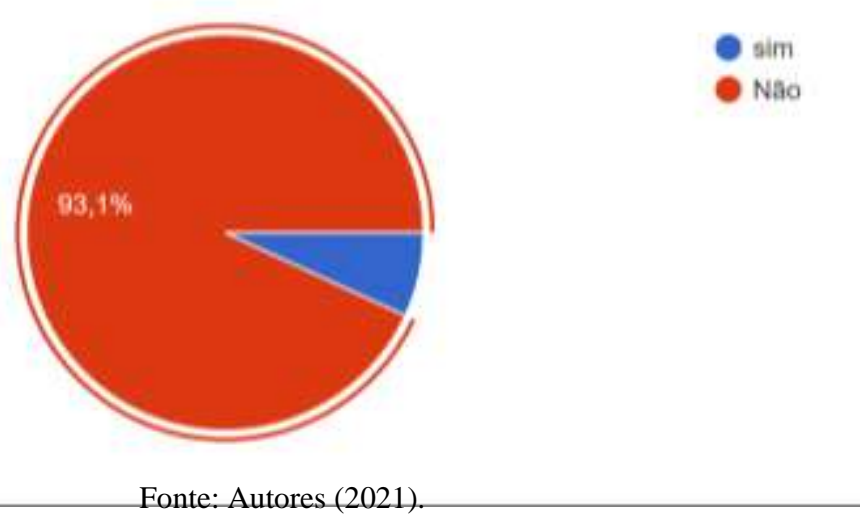

Buscamos perceber se, em sua formação inicial, o pedagogo é sensibilizado para auxiliar na identificação de uma possível criança com depressão: "Como estudante da graduação, você recebeu orientações que o auxiliem na identificação de possíveis sintomas de depressão em uma criança?" $86,2 \%$ dos sujeitos de pesquisa responderam “não", o que demonstra que a sensibilização para um olhar mais atento a um possível quadro de depressão infantil ainda deixa muito a desejar na formação inicial do professor. Os dados estão apresentados na Figura 3: 
Figura 3. A formação inicial contribui para auxiliar o professor na identificação de possível criança com depressão.

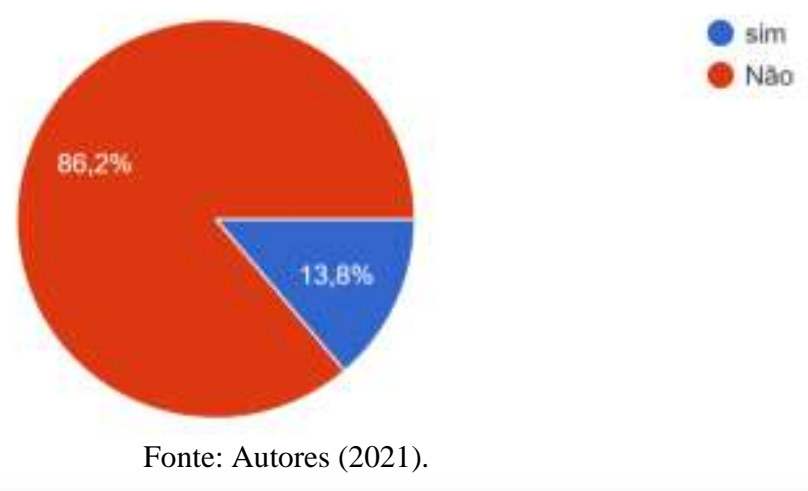

Buscamos ainda perceber se os sujeitos de pesquisa julgam o tema relevante para sua formação inicial: "Você considera importante que a Universidade sensibilize os futuros pedagogos para situações de depressão infantil?” E todas as respostas foram afirmativas, o que demonstra a relevância do tema para a formação inicial do professor que lidará com crianças em seus primeiros anos de vida escolar. Os dados estão apresentados na Figura 4:

Figura 4. Importância de a Universidade sensibilizar futuros pedagogos para situações de depressão infantil.

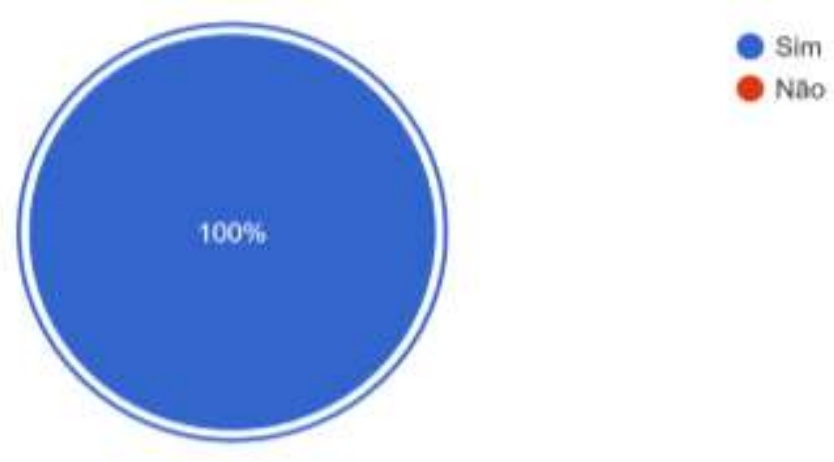

Fonte: Autores (2021).

Diante disso, a nossa hipótese é de que a formação inicial do pedagogo não prepara esse profissional para lidar com situações de depressão infantil. Acreditamos que é de grande relevância que o professor tenha conhecimentos básicos sobre essa doença em crianças. Isso potencializará sua sensibilidade aos sinais, para que possa auxiliar fazendo os encaminhamentos necessários e, assim, caso a criança esteja acometida pela depressão, possa ser tratada o quanto antes.

\section{Considerações Finais}

Ao longo do trabalho, contextualizamos como a depressão tem sido compreendida e manifestada na contemporaneidade e na vida das crianças. Identificamos que a depressão tem sido caracterizada como um transtorno do humor, mas pode erroneamente ser identificada e tratada a partir de uma tristeza natural presente nos ciclos da vida e até em formas extremas de melancolia. por ora, a banalização da depressão a um sentimento de tristeza e a falta de clareza acerca da história clínica e pessoal tem repercutido numa excessiva medicalização da vida. constatamos também que o avanço do progresso, da globalização, que trazem novas formas de vida, tem sido um desencadeador para os transtornos do humor. o excesso de relações virtualizadas tem provocado um culto ao narcisismo, gerando em contrapartida, um desamparo nas 
pessoas. especialmente no atual contexto de pandemia da covid 19, em que as pessoas têm enfrentado situações limite, numa eminente ameaça de morte, as alterações de humor tem sido uma constante.

Evidenciamos vários tipos e várias causas de depressão que, geralmente, são informações desconhecidas por pais, professores e demais componentes escolares, dificultando, assim, que as crianças que tenham ou tendem a ter a doença recebam os cuidados necessários. a família como primeira comunidade é a maior responsável pelo bem estar da criança, mas infelizmente nem sempre, por motivos diversos, os responsáveis conseguem perceber os sinais.

A depressão infantil pode ser bem difícil de identificar, pois a criança possui dificuldade de processar o que se passa, não sabe se é comum, se todos sentem o mesmo e não consegue relatar ao certo o que sente, e seus sinais podem passar despercebidos. também é importante falar sobre o estereótipo: não são todos os depressivos que terão o mesmo sentimento de tristeza, melancolia, às vezes, crianças podem ter alteração de comportamento, mostrando-se grosseiras, agressivas, o que pode fazer com que a doença passe despercebida, sob o rótulo de mal comportamento.

Em nossa pesquisa, pudemos verificar que, apesar de julgarem como importante que sua formação contemple conhecimentos básicos sobre a depressão infantil, a maioria dos estudantes, que estão no último semestre do curso de pedagogia e, portanto, em breve estarão em sala de aula, avaliam as orientações recebidas sobre o tema como insuficientes, portanto, não se sentem preparados para identificar ou lidar com crianças acometidas pela doença.

A depressão pode causar dificuldades de aprendizagem para a criança, já que a doença influencia na autoestima, no humor e no interesse pelas coisas em geral. nessa perspectiva, consideramos fundamental que os professores tenham, no mínimo, conhecimentos básicos sobre a doença, pois a sensibilidade para reconhecer os sinais pode resultar no atendimento necessário à criança antes de a doença agravar-se, possibilitando ainda, a minimização significativa de dificuldades em seu processo de ensino-aprendizagem. Nesse sentido, faz-se necessário mais estudos voltados a essa temática já que é de suma importância que o professor seja preparado para identificar sintomas suspeitos de depressão em crianças.

Devido o despreparo dos professores para identificar ou lidar com crianças acometidas pela doença sugere-se que mais estudos sejam realizados nessa área com a finalidade de ampliar os conhecimentos sobre este transtorno e suas consequências para a vida da criança, que muitas vezes não diagnosticado gera prejuízos em diversos campos de sua vida.

\section{Referências}

American, P. A. (1994). Manual de Diagnóstico e Estatística de Distúrbios Mentais DSM-IV. Manole.

American, P. A. (2014). Manual de Diagnóstico e Estatística de Distúrbios Mentais DSM-V. Techbooks.

Andriola, W. B. \& Cavalcante, L. R. (1999). Avaliação da depressão infantil em alunos da pré-escola. Psicologia: Reflexão e Crítica. 12(2)

Bahls, S. C. (2004). A depressão em crianças e o seu tratamento. Lemos.

Baptista, M. N. (1999) Sintomatologia, diagnóstico e características da depressão no adolescente In Baptista, M.N \& Assumpção, F. B. Depressão na adolescência: Uma visão multifatorial. EPU

Baptista, C. A. \& Golfeto, J. H. (2000) Prevalência de depressão em escolares de 7 a 14 anos. Revista de Psiquiatria Clínica, (27)5, 253-256.

Baptista, M. N. Nelson H. F. \& Fernanda G. (2018). Análise via tri da Escala Baptista de Depressão infanto-Juvenil e do inventário de Depressão infantil. Revista Psicologia Pscico. (48)4, 339-347. https://doi.org/10.15448/1980-8623.2018.4.26866.

Barbosa, G. A. \& Lucena, A. (1995). Depressăo infantil. Infanto, 2, 23-30.

Bauer, A. D. (2007). Sintomatologia depressiva infanto-juvenil: aspectos psicológicos e relações com o desempenho acadêmico Bauer. 2007. 182f. Dissertação (Mestrado em Educação) - Universidade Federal do Paraná, Curitiba.

Belk, A. \& Alford, B. (2011). Depressão: causas e tratamento. Artmed.

Birman, J. (2005). Mal estar na atualidade: A psicanálise e as novas formas de subjetivação. (5a ed.), Civilização Brasileira.

Cid 10. (1993). Classificação de Transtornos Mentais e de Comportamento: Critérios diagnósticos para pesquisa. Artes Médicas. 
Cruvinel, M. (2003). Depressão infantil, rendimento escolar e estratégias de aprendizagem em alunos do ensino fundamental. 143f. Dissertação (Mestrado em Educação) - Universidade Estadual de Campinas (UNICAMP), Campinas.

Cruvinel M. \& Boruchovitch E. (2003) Depressão Infantil: uma contribuição para prática educacional. Revista Semestral da Associação Brasileira de Psicologia Escolar e Educacional, (7)1, 77-84.

Curatolo. E. \& Brasil, H. (2005) Depressão na infância: peculiaridades no diagnóstico e tratamento farmacológico. J Bras Psiquiatr (54)3, 170-176. 21 1999 from http://www.fiocruz.br/media/bipolar_heloisa_brasil.pdf

Darwich, R. A. \& Tourinho, E. Z. (2005). Respostas emocionais à luz do modo causal de seleção por consequências. Revista Brasileira de Terapia Comportamental e Cognitiva, 7(1), 107-118. https://doi.org/10.31505/rbtcc.v7i1.4

Del P. J.A. (1999) Conceito e diagnóstico. Rev. Bras. Psiquiatr. (21)1, http://www.scielo.br/pdf/rbp/v21s1/v21s1a03.pdf ISSN 1516-4446.

Fonseca, A. C. (1998). Problemas Emocionais nos Anos do Ensino Básico. Revista Portuguesa de Pedagogia.

Freud, S. (1914). Sobre o Narcisismo: uma introdução. In A história do movimento psicanalítico, artigos sobre a metapsicologia e outros trabalhos. Imago, (Edição Standart brasileira das obras psicológicas completas de Sigmund Freud, (14)).

Freud, S. (1992) Luto e melancolia. In Freud, S. Obras psicológicas - antologia. Peter Gay (Org). Imago Editora.

Hemery \& Jean J. R. (2008). Depressão infantil. Revista do Professor - n. 80.

Lafer, B. Almeida, O. P., Fráguas J. R., Renério, \& Miguel, E. C. (2000). Depressão no ciclo da vida. Artes Médicas Sul.

Lemos, P. \& Marback, R. F. (2016) Depressão infantil e impactos no desenvolvimento do indivíduo. Seminário estudantil de produção acadêmica. http://www.revistas.unifacs.br/index.php/sepa/article/view/4347

Lima, R. F. \& Mello, R. J. L., Massono, I., \& Ciasca, S. M. (2006). Dificuldades de aprendizagem: queixas escolares e diagnósticos em um serviço de Neurologia infantil. Revista Neurociências

Maia, M. S. (2002) Um tapete vermelho para a angústia: Considerações sobre a clínica psicanalítica e a contemporaneidade. In Transgressões. Espaço Brasileiro dos Estudos Psicanalíticos.

Marcelli, D. (1998). Manual de Psicopatologia da Infância de Ajuriaguerra. (5a ed.), Artmed.

Miller J. A. (2003). O livro de referência para a depressão infantil. MBooks do Brasil, 2003.

Milavic, G. (1985). Do chronicalle ill and handicapped children become depressed? Developmental Medicine \& Child Neurology, 27, 675-685

Nakamura, E. \& Santos, J. Q. dos. (2007). Depressão na infância: abordagem antropológica. Rev. Saúde Pública. https://doi.org/10.1590/S003489102006005000011

Palangana, I. C. (1995). Desenvolvimento e Apendizagem em Piaget e Vygotsky (A relevância social). Plexus.

Piaget, J. (1967). Seis estudos de psicologia. Trad. Maria A.M. D’Amorim, Paulo S.L. Silva. Forense, 146p.

Rehm, L. P., \& Sharp, R. N. (1999). Estratégias para a depressão infantil. Em: M. Reinecke, F. Dattilio \& Artur Freeman, Terapia Cognitiva com crianças e adolescentes. (91-104). Artes Médicas.

Rodrigues, I. O. et al (2016). Predicting signs of depression in children with specific learning disorders. Rev. CEFAC, (18) 4, 864-875.

Soares, M. U, (2003). Estudos das variáveis do desenvolvimento infantil em crianças com e sem o diagnóstico de depressão. Tese de Doutorado NãoPublicada, Pós-graduação em Ciência do Movimento Humano, Universidade Federal de Santa Maria.

Vygotsky, L. S. (1988). Aprendizagem e desenvolvimento intelectual na idade escolar. In: Vygotsky, L. S., Luria, A. R., Leontiev, A. N. Linguagem, desenvolvimento e aprendizagem. Tradução de Maria da Penha Villalobos. (2a ed.), Ícone. 